\title{
A Continuous Test Method for Dynamic Change of Real Mesostructures of Soil
}

\author{
Xiaoxu Qian, ${ }^{1,2,3}$ Xin Liu $\mathbb{D}^{1,},{ }^{1,2}$ Yunlong Yao, ${ }^{1,2}$ Shikun Pu, ${ }^{1,2,4}$ Ke Sheng, ${ }^{1,2}$ Guisen Wang, \\ Baoning Hong, ${ }^{1,2}$ and Dingyu Feng ${ }^{3}$
}

${ }^{1}$ Key Laboratory of Ministry of Education for Geomechanics and Embankment Engineering, Hohai University, Nanjing 210024, China

${ }^{2}$ Institute of Tunnel and Underground Engineering, Hohai University, Nanjing 210024, China

${ }^{3}$ School of Urban and Civil Engineering Sciences, Nanjing University Jinling College, Nanjing 210089, China

${ }^{4}$ Army Engineering University of PLA, Nanjing 210007, China

Correspondence should be addressed to Xin Liu; liuxin100@hhu.edu.cn

Received 17 August 2021; Accepted 21 December 2021; Published 24 January 2022

Academic Editor: Lei Hou

Copyright ( 2022 Xiaoxu Qian et al. This is an open access article distributed under the Creative Commons Attribution License, which permits unrestricted use, distribution, and reproduction in any medium, provided the original work is properly cited.

\begin{abstract}
The regularity of dynamic change of real mesostructures of soil is the foundation of the macro- and mesointegrated research. Mesoscale research about continuous image acquisition in real soils, identifying and quantifying mesostructures, is the subject of current interest. Soil mesostructure measurement method is the basis of modeling, and the development of rapid, direct, and lower-cost methods has great practical value for engineering practice. Combined with conventional triaxial loading test equipment, optical measurement, mesoscopic imaging tracking system, and digital image technology, a new method for measuring the dynamic change of the soil mesostructure is designed. This integrated approach to observation and acquisition is realized by direct observation and continuous image capture for dynamic change of real mesostructures of soil. The methods are used to analyze the high compressibility of a certain clay, shear zone development of cement soil, and erosive effects of ecological soil in order to investigate the continuous variation of mesostructures during the shear test. The aim of this paper is to provide a simple, straightforward, continuous, and low-cost test method for revealing the characteristics of consecutive change of real mesostructures of soil in the conventional triaxial test.
\end{abstract}

\section{Introduction}

The regularity of dynamic change of real mesostructures of soil is the foundation of the macro- and mesointegrated research [1-4]. Investigating the characterization of mesostructural parameters can provide sufficient evidence for macro- and mesointegrated modeling schemes [1, 5-7]. As soil deformation is gradual, the change of real mesostructures is continuous $[8,9]$. So, the characteristics of consecutive change of mesostructures' parameters are the actual embodiment of macroscopic law during load and deformation.

Researching the evolution law of the internal structure of soils during loading is the subject of current interest. The test method decides the observation. Mercury intrusion test is used to measure the pore size and distribution of the soil, but there is a limitation of the pore size $[10,11]$. Scanning electron microscope (SEM) [12, 13] and environmental scanning electron microscope test (ESEM) $[10,11]$ are used to observe the arrangement of particles and pores of the sample surface and are high in technical requirements for sample preparation [11]. Nondestructive testing methods as computed tomography (CT) [14-17] and nuclear magnetic resonance (NMR) $[18,19]$ are observed indirectly, and sampling strategy will affect reconstruction quality [20]. Besides, the larger the sample number, the higher the cost [21, 22]. Due to the adoption and nondestructive photogrammetry [23-26], the deformation measurement in $2 \mathrm{D}$ or $3 \mathrm{D}$ scale during triaxial testing is widespread in use. However, research shows that digital images can quantify and characterize mesostructure 
via $\mathrm{CCD}$ detectors combined with the optical microscope $[7,12]$. And it is straightforward and cost-effective [27-29].

Dynamic change of real mesostructures of soils is the embodiment of macroscopic property. For this reason, Zhang et al. [30], Tang et al. [31], and Wang et al. [32] characterized the mesostructures' evolution by digital images observed from a glass window on pressure vessels, but the soil sample has limitations. Shao et al. [8] and Tang et al. [33] measured the shear band evolution by tracking the label on the sample surface, which cannot observe the mesostructure. Wang et al. [9] and Rechenmacher and Cetina [34] proposed the image-finite-element method to characterize the mesostructures' evolution during loading, but the dynamic change of objects is simulation. Lanting et al. [35] achieved the visualization of the shear band evolution in a laboratory slope model test using transparent soil, but the sample was surrogation. Salazar and Coffman [36] investigated the shear band evolution by 360-degree coverage of sample in the triaxial compression test; Mehdizadeh et al. [37] proposed the shear band evolution was discontinuous in this test method. However, the above research efforts indicate that the testing methods for dynamic change of real mesostructures of soil lack being simple, straightforward, continuousness, and of low cost.

A methodology of dynamic change of real mesostructures of soil is introduced based on photogrammetry. Through the design of the semicylindrical loading chamber, the real mesostructure of the soil sample under three-dimensional loading is observed directly. Based on automatic tracking technology, continuous observation and acquisition of real mesoscopic structure dynamic changes are realized. Combined with triaxial equipment and observation equipment, the simultaneous observation and measurement of macro- and mesotests in the process of three-dimensional loading of soil are realized. It also provides equipment and method support for macro- and mesointegrated observation.

Furthermore, the automatic tracking of dynamic change of pores (particles) and cracks is realized by using photogrammetry. Then, statistical parameters, such as probability entropy and fractal dimension, are introduced to describe the pores (particles) and cracks direction distribution, area distribution, and complexity variation, respectively, by image processing technologies. The methods are used to analyze the high compressibility of a certain clay, shear zone development of cement soil, and erosive effects of ecological soil in order to investigate the continuous variation of mesostructure during the shear test. The results show that the characteristics of mesostructures correspond to the macroscopic law using this method. The aim of this paper is to provide a continuous and reliable test method for the characteristics of dynamic change of real mesostructure of soil in the conventional triaxial test.

\section{Experimental Design and Testing Procedure}

2.1. Loading Chamber. To measure the dynamic change of internal structure of the soil in conventional triaxial test, divide the traditional cylindrical soil sample from the symmetrical surface, and the semicylindrical shape is taken as the test object, as shown in Figure 1(a). The loading system is the same as the conventional triaxial test. The pressure chamber is shown in Figure 1, which is made into a semicylindrical type. Axial pressure $\sigma_{1}$ is given by the load sensor and displacement sensor and imposed by the movement of the semicylindrical loading cap assembly on the worm when it touches the soil sample. The capacity of the load sensor is $5 \mathrm{kN}$ with a resolution of $1 \mathrm{~N}$, and the displacement sensors is $55 \mathrm{~mm}$ with a resolution of $0.01 \mathrm{~mm}$. Confining pressure $\sigma_{3}$ is applied by air pressure in the rubber air cell, generated by high-pressure gas, and controlled by the lateral confining pressure sensor with a capacity of $1.0 \mathrm{MPa}$ and resolution of $5 \mathrm{kPa}$, as shown in Figure 1(b).

The confining pressure of the observation plane is applied by the transparent tempered glass, which is fixed on the semicylindrical pressure chamber by screws. As shown in Figure 1(c) the observation plane is the axial symmetric plane from the cylindrical soil sample of the conventional triaxial test, $\sigma_{1}$ is vertical stress, and the stresses on the observation plane $\sigma$ are equal to confining pressure $\sigma_{3}$. The stress states of the observation plane are similar to the axial symmetric plane of cylindrical soil samples of the conventional triaxial test. Thus, the simple, direct observation of the internal structure of soils can be realized in this way.

2.2. Sample Preparation. The soil sample is prepared according to the triaxial test, and the cylindrical soil sample is $39.1 \mathrm{~mm}$ in diameter and $80 \mathrm{~mm}$ in height, which is cut with a foil sampler. Tang et al. [31] and Wang et al. [32] observe the mesostructure of soil through transparent glass plates, which attach to the observation surface. Wang et al. [9] divided the cylindrical sample into two parts from the symmetrical surface and obtained the real mesostructure of soil through the symmetrical plane. Based on this, a semicylindrical soil sample is prepared, and the symmetry plane of a cylindrical soil sample is selected as the observation surface, which is observed through a transparent glass plate.

When the cylindrical soil sample is divided, in order to ensure the shape of the symmetrical plane, it is concluded after repeated tests; that is, cut along the symmetrical plane of the cylindrical soil sample vertically; use mechanical cutting method about $3 \mathrm{~cm}$ at first; then, score the outer surface of the cylinder sample along the cutting line; and then, open it along the cutting line into half-cylinder. At this time, the divided part of the soil sample without the mechanical cutting method is a fresh section, and images with real mesostructure characteristics can be obtained [9, 38]. A magnifying glass should check the observation plane whether loose particles remain on. To remove the loose particles on the surface, thinly coat the surface with glue; then tear it off slightly; and blow it off the surface with a rubber ball to obtain a fresh surface. The operation process should be gentle and careful.

2.3. Microdevices. Localization of deformation is of the order of magnitude as the size of particles on the mesoscopic scale $[39,40]$. Under the definition of Cotecchia et al. [1], the side size of the mesostructure's parameters is 


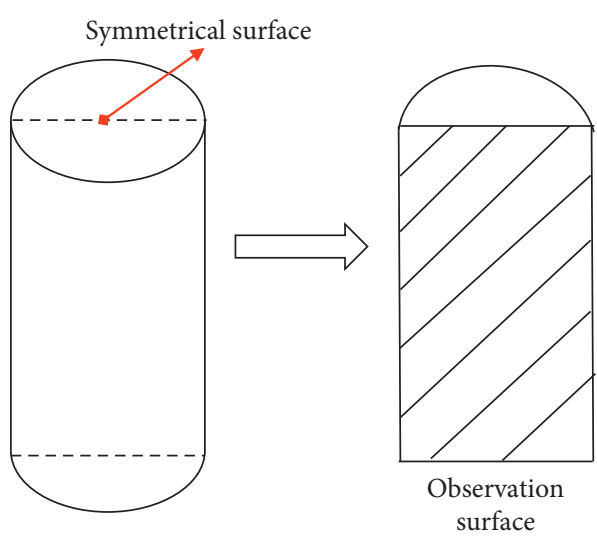

(a)
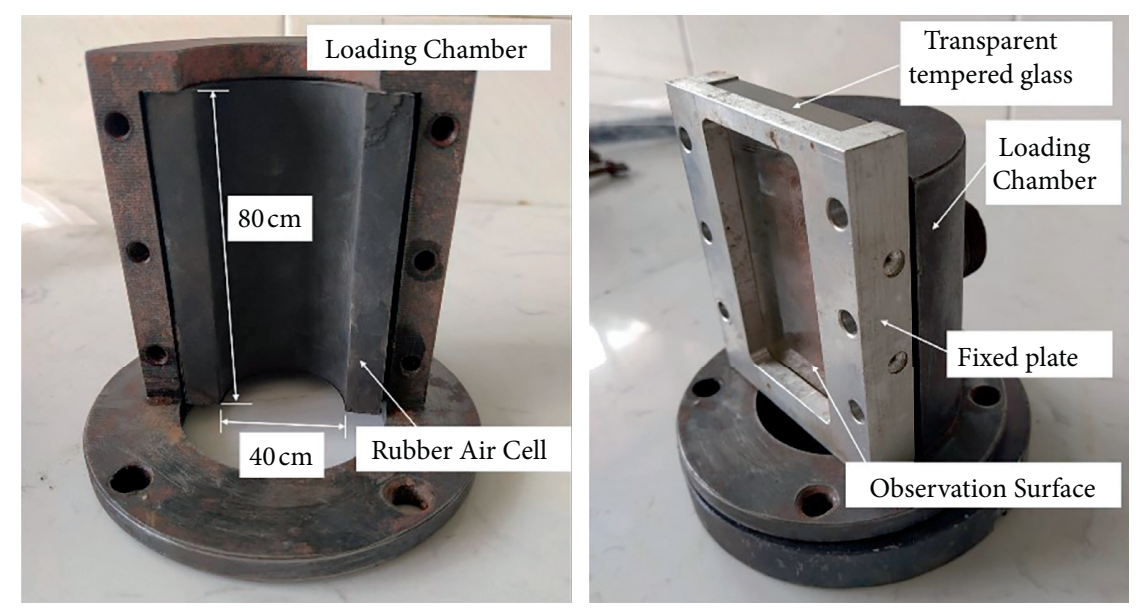

(b)

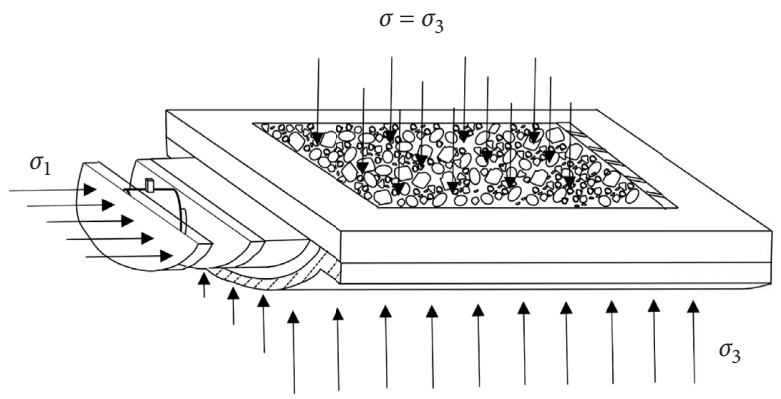

(c)

FIGURE 1: Schematic diagram of direct observation. (a) Schematic diagram of soil sample divided into two parts; (b) pressure chamber; (c) stress states of the observation plane.

$0.1 \mathrm{~mm} \sim 10 \mathrm{~mm}$. Therefore, microdevices use a noncontact remote microscope: Questar Long Working Distance Microscope QM100. Main function parameters are working distance with $15-35 \mathrm{~cm}$; resolution of $1.1 \mu \mathrm{m}$; maximum magnification with $300 \times$; the field of view with $0.375-8.0 \mathrm{~mm}$.

2.4. Automatic Tracking of Observation Area. According to the microscope parameters, the observation area is about $1 \mathrm{~mm}^{2}$ when the magnification is 150 times. The objects of mesostructure are dynamic change during loading. If the observation is not tracking the objects, the dynamic changing objects will be moved out of view as the field of view is only $\mathrm{mm}^{2}$. Thus, the dynamic change of real mesostructures of soil needs continuous measurement. Many previous studies $[27,29,34]$ have shown that displacement information can be obtained by matching the pixel subset, tracking clusters of uniquely colored pixels.

Image capture with intense overlapping subsets makes spaced center to center just a few pixels apart as Figure 2(a). " $m n$ " is an objective area as center point coordinate is $(x, y)$. To track the pixel subset recognize correlation coefficients of the gray value of " $m n$ " from $k t$ to $(k+1) t$ frame using the following equation:

$$
C(x, y)=\frac{\left[N \sum \sum(f \cdot g)-\sum \sum f \cdot \sum \sum g\right]^{2}}{\left[N \sum \sum f^{2}-\left(\sum \sum f\right)^{2}\right] \cdot\left[N \sum \sum g^{2}-\left(\sum \sum g\right)^{2}\right]},
$$

where $f$ and $g$ are gray values of $k$ frame, i.e., $f[(x, y) ; k t]$; $k+1$ frame, i.e., $f[(x, y) ;(k+1) t] . N$ is the number of pixels. " $M N$ " is the retrieval area. The best match for " $m n$ " in " $M N$ " is the maximum of correlation coefficients of gray value from $k t$ to $(k+1) t$ frame [41]. The method is illustrated conceptually for a specimen in Figure 2(b). $\Delta x$ is horizontal displacement, and $\Delta y$ is the vertical displacement of the center point in the objective area. But the problem is how to realize the automatic tracking of observation by microdevices. Put the microscope on a platform that can move by stepping motor control driver in $3 \mathrm{D}$, as shown in Figure 2(c).

Using equations (2) and (3), turn the relative distance of pixel subset into pulse number of stepping motor control driver.

$$
\begin{aligned}
& n_{x}=\frac{\Delta x}{K_{x}}, \\
& n_{y}=\frac{\Delta y}{K_{y}},
\end{aligned}
$$




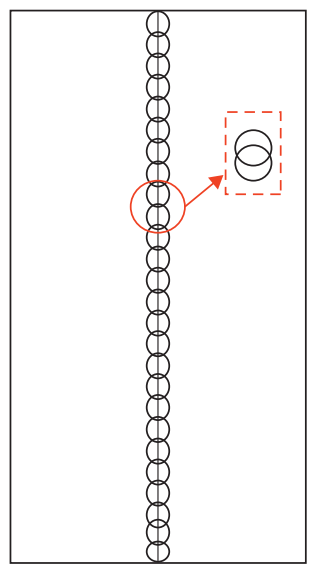

(a)

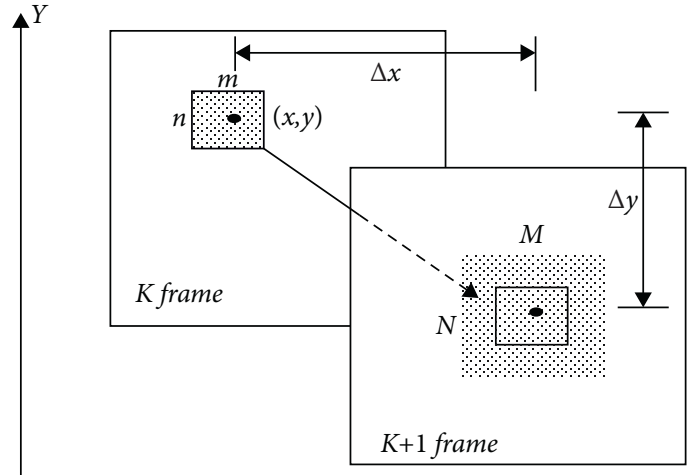

(b)

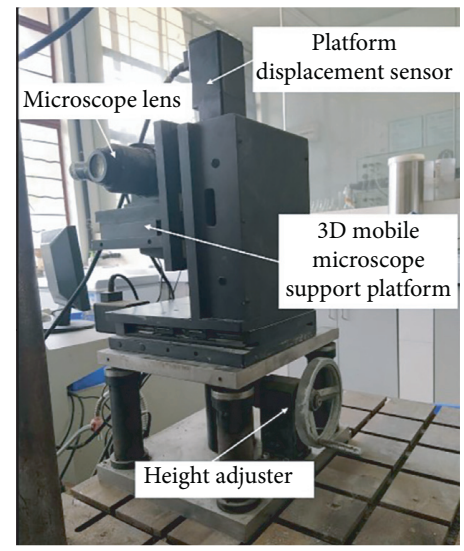

(c)

FIgURE 2: Schematic diagram of automatic tracking of observation: (a) distribution of objective area; (b) schematic diagram of automatic observation tracking; (c) automatic 3D tracking platform.

where $n_{x}$ and $n_{y}$ are pulse numbers of $x$ - and $y$-direction and $K_{x}$ and $K_{y}$ are calibration coefficients of $x$ - and $y$-direction for stepping motor control driver.

The major technical specifications of the platform in 3D are listed in Table 1.

2.5. Image Fusion. The soil sample surface is less gray level different, and shallow depth of field influences the quality of the digital image. To solve this problem, get the images with different magnifications. And then, the image is decomposed into its low-frequency approximation and horizontal, vertical, diagonal edges using wavelet transforms [42] to image fusion, as Figure 3.

$C_{3}$ is a low-frequency component of information of the whole image; $D_{j}^{k}$ is edge information where $j$ is the scale of decomposing $(j=1,2,3)$, and $k$ is an orientation of edges ( $k=h, v, d$ as horizontal, vertical, and diagonal).

First, merge the subband coefficients of the corresponding frequency content. The edge of the image is the high frequency of frequency field. $w_{j, k}^{i}$ are the high-frequency coefficients in edge orientation $(k)$ with different scale $(j)$. Choose maximum $w_{j, k}^{i}$ from two images before and after the following equation:

$$
\widehat{w}_{j, k}=\left\{\begin{array}{l}
w_{j, k}^{1}, a b s\left(w_{j, k}^{1}\right)>a b s\left(w_{j, k}^{2}\right), \\
w_{j, k}^{2}, a b s\left(w_{j, k}^{1}\right) \leq a b s\left(w_{j, k}^{2}\right) .
\end{array}\right.
$$

Choose the maximum value of the low-frequency coefficients from before images and after (i.e., $C_{3}^{1}$ and $C_{3}^{2}$ ), that is, $\widehat{C}_{3}$ as $\widehat{C}_{3}=\max \left(C_{3}^{1}, C_{3}^{2}\right)$.

Then, generate a synthesized fused image by the inverse transform of $\widehat{C}_{3}$ and $\widehat{w}_{j, k}$, shown in Figures 4(a) and 4(b). For evaluating its reliability, fused images in Figure 4(c) are compared with photoshopped images in Figure 4(d).

As Figures 4(c) and 4(d) show, they are similar, while Figure 4(d) has the edges of the image mosaic, which influences the identification of the mesostructure's parameters in this place.

2.6. Image Segmentation. The research objects of mesostructure are particles, pores, and fissures mostly [13]. Image segmentation is mainly based on identifying isolated regions in a binary image $[12,43]$, and black pixels represent pores in the binary image. Image binarization is done using the Mean Gray Level algorithm as in the following equations: 
TABLE 1: Main technical specifications of the automatic tracking apparatus.

\begin{tabular}{lcccc}
\hline $\begin{array}{l}\text { Max static torque of coupling } \\
(\mathrm{N} \cdot \mathrm{m})\end{array}$ & $\begin{array}{c}\text { Revolutions of stepping } \\
\text { motor }(\mathrm{rpm})\end{array}$ & $\begin{array}{c}\text { Size of platform } \\
(\mathrm{mm})\end{array}$ & $\begin{array}{c}\text { The maximum range of } \\
\text { platform }(\mathrm{mm})\end{array}$ & $\begin{array}{c}\text { Adjustment accuracy } \\
(\mathrm{mm})\end{array}$ \\
\hline 0.45 & 390 & $260 * 300$ & $25 * 25$ & 0.01 \\
\hline
\end{tabular}

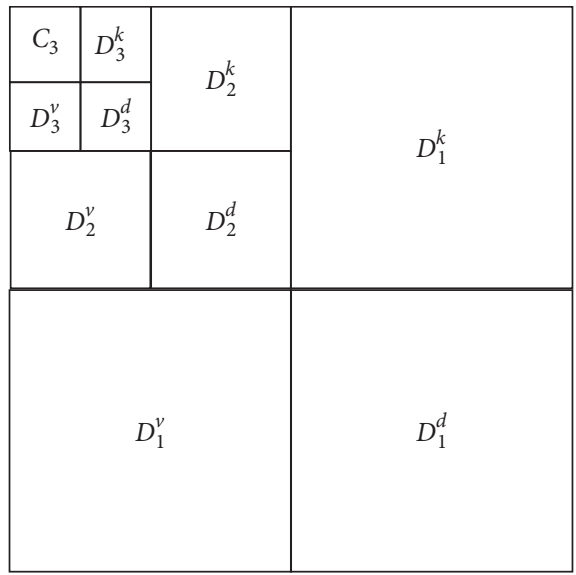

Figure 3: Wavelet transforms to image fusion.

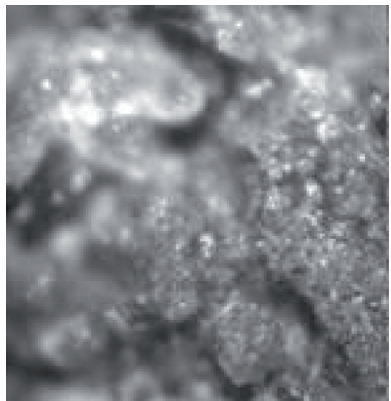

(a)

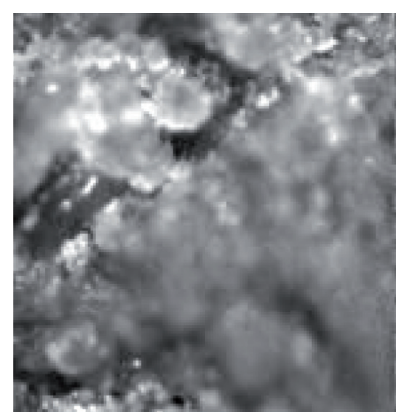

(b)

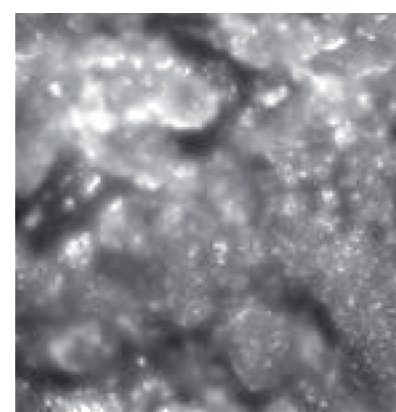

(c)

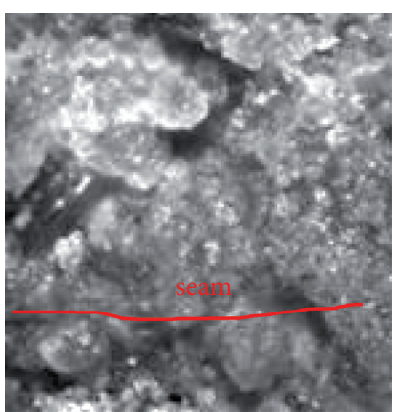

(d)

FIgURE 4: Image fusion: (a) (k) frames; (b) $(k+1)$ frames; (c) fused image by wavelet transforms; (d) fused image by Photoshop.

$$
\begin{aligned}
f_{t}(x, y) & = \begin{cases}255, & f(x, y)>\theta \\
0, & f(x, y) \leq \theta\end{cases} \\
\bar{\theta} & =\sum_{i=0}^{1280} \sum_{j=0}^{1024} \frac{\theta_{i, j}}{1280 \times 1024}
\end{aligned}
$$

where $\theta_{i, j}$ is the gray value of the pixel, $\bar{\theta}$ is the average gray of the image, $f(x, y)$ is the gray value of image point $(x, y)$, and $f_{t}(x, y)$ is the new gray value of image point $(x, y)$. Select the image resolution as $1280 * 1024$. Figure 5 is the image segmentation in which the gray threshold value is 108 , the particles gray value is 255 , and the pores gray value is 0 .
2.7. Mesostructural Parameters Characterization. Characterization of mesostructures' parameters includes area ratio, fractal dimension, probability entropy, Euler number, Roundness, and so on:

(i) Area ratio is calculated by the number of pixels of the mesostructures' parameter to the total number of pixels in the image. The area ratio of pores/fissures has shown the evolution law of inner defect.

(ii) Fractal dimension using sandbox method of the fractal theory which Mandelbrot establishes. The sandbox method has divided the image into an orthogonal grid, with the length for "a." The logarithm of the grid numbers of particles and pores is 


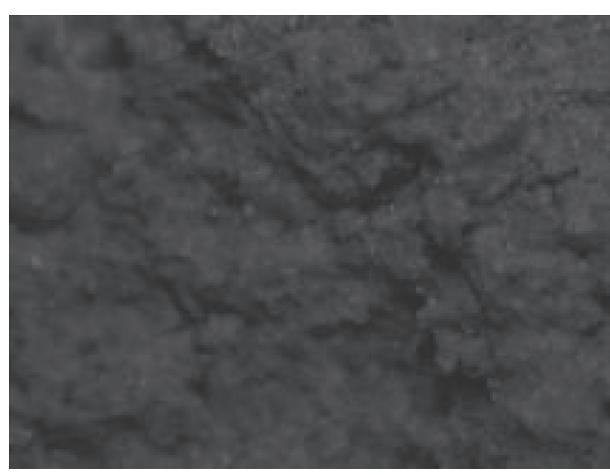

(a)

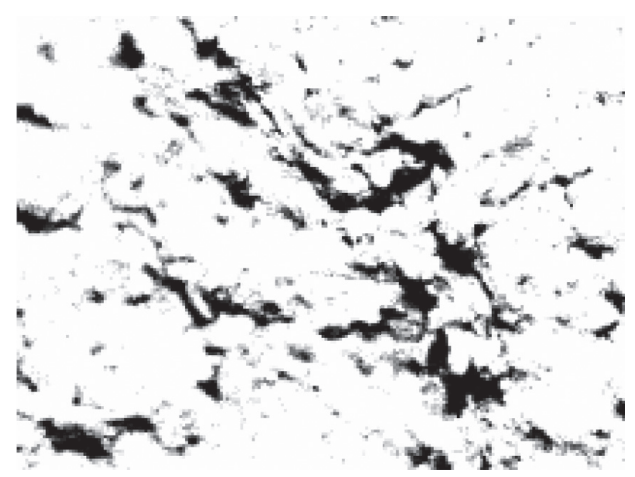

(b)

FIGURE 5: Image segmentation: (a) soil image (magnified about 150 times); (b) binary image (black represents the pores).

linearly related to the logarithm of the grid length. The slope of linear parts is the fractal dimension. The larger the fractal dimension of the object distribution, the greater the degree of dispersion.

(iii) Direction distribution is described by probability entropy [4, 12], as equation (7). The larger the probability entropy, the more disordered the direction distribution.

$$
H=-\sum_{i=1}^{n} p_{i}(\alpha) \log _{n} p_{i}(\alpha)
$$

where $\alpha$ is the azimuth of the object's longest strings, $p_{i}$ is the probability of appearance about the object in a certain azimuth interval, and $n$ is the number of azimuth intervals.

(iv) Roundness is done using the following equation to describe the proximity with the shape of object and circle. $R$ is one as the shape of the object is a circle, as the following equation:

$$
R=\frac{4 \pi S}{L^{2}}
$$

where $S$ is the pixel area of the object, and $L$ is the pixel perimeter of the object.

(v) Euler number " $O$ " is introduced to describe the section connectivity using equation (9). Mark the image backgrounds as 0 and the object as 1 .

$$
O=n(l)-n\left(\begin{array}{l}
1 \\
1
\end{array}\right)-n\left(\begin{array}{ll}
1 & 1
\end{array}\right)+n\left(\begin{array}{ll}
1 & 1 \\
1 & 1
\end{array}\right)
$$

In the formula, $n(l)$ is the number of the pixels of an object, $n\left(\begin{array}{l}1 \\ 1\end{array}\right)$ it is the number of pixels of the object as vertically adjacent, $n\left(\begin{array}{ll}1 & 1\end{array}\right)$ is the number of the pixels of the object as horizontally adjacent, and $n\left(\begin{array}{ll}1 & 1 \\ 1 & 1\end{array}\right)$ is the number of the pixels of the object as surrounding adjacent.
A program, Geo-Image, has been developed with Microsoft Visual C++ 6.0 to compute the mesostructures' parameters accurately.

2.8. Testing Process. A sketch of the entire apparatus is shown in Figure 6. The characteristics of dynamic change of real mesostructures can be obtained by using the apparatus.

During the test, there are some problems as follows.

(i) The observation glass is misting during loading when soil has high moisture content, causing image blurring. In order to mitigate its effects, apply petroleum jelly to the inside of the observation glass before testing. After image collection, median filtering is used for image denoising and then sharpening the image by high pass filtering. As Figure 7 shows, image binarization of soil samples with high moisture content after using denoising and sharpening to process image is useful for identification of mesostructures.

(ii) When the point is changing, use an adjustable test platform and platform in 3D (Figure 6) to change the position of the microscope, thus to realize the observation of the interest area of the soil sample.

\section{Test Results and Discussion}

3.1. High Compressibility of a Certain Clay. A certain clay compression coefficient is higher than normal from an embankment backfill, as shown in Table 2. According to the Chinese National Standard "standard for engineering classification of the soil" [44] (Chinese 2007) and the Chinese National Standard "Test Methods of Soils for Highway Engineering" [45], it is low liquid limit clay and not expansive soil. The reason for its high compressibility cannot be explained from the macroscopic characterization.

In order to investigate the causes of high compressibility, the mineral composition was analyzed by XRD (X-ray diffraction) as shown in Table 3. Smectite content has a relationship with swelling [46]; the compression coefficient of T3006 is lower than T3813. Still, smectite content is higher than T3813, which means that it needs more effective revelation. 


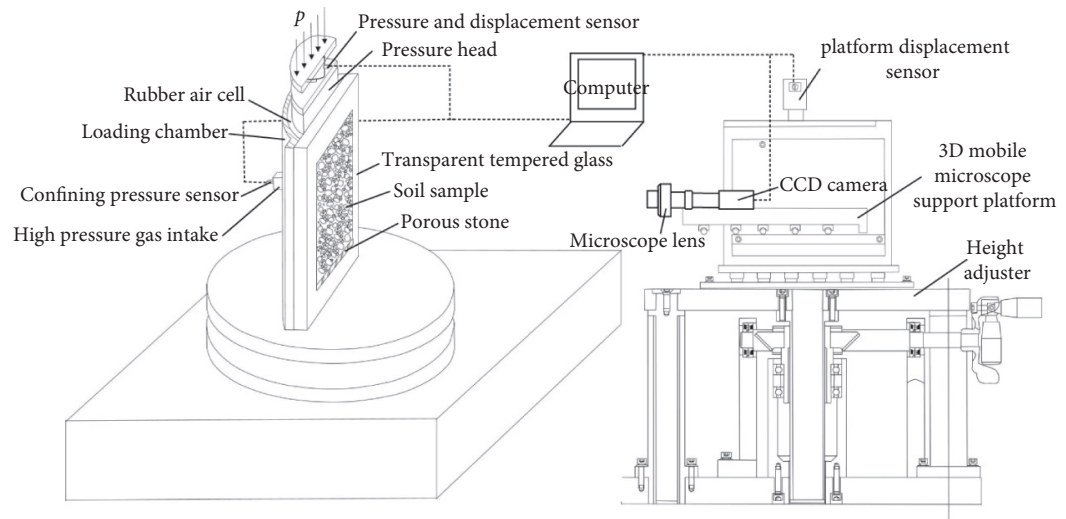

(a)

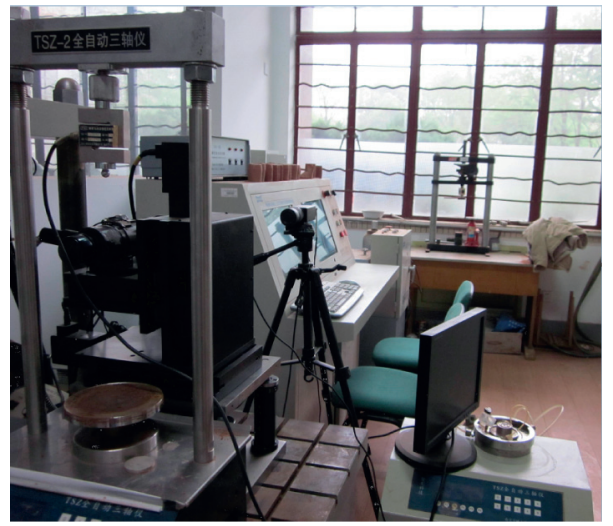

(b)

Figure 6: Apparatus for a continuous test of dynamic change of real mesostructures of soil. (a) Schematic diagram of test system; (b) real image of the test system.

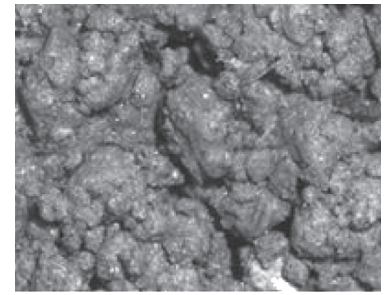

(a)

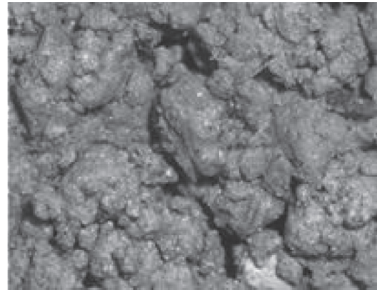

(b)

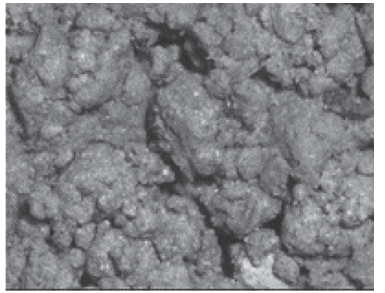

(c)

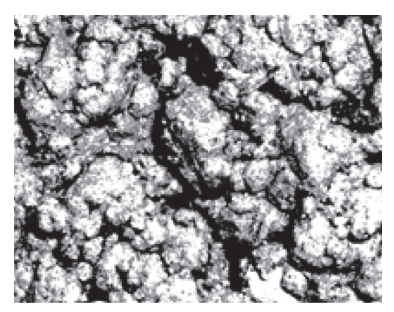

(d)

FiguRe 7: Image process of high-water content sample: (a) original image; (b) image denoising; (c) image sharpening; (d) image binarization.

TABle 2: The physical properties of backfill soil.

\begin{tabular}{|c|c|c|c|c|c|c|c|c|c|}
\hline Code & $\begin{array}{c}\text { Water } \\
\text { content } \\
\omega(\%)\end{array}$ & $\begin{array}{l}\text { Natural } \\
\text { density } \\
\rho\left(\mathrm{g} / \mathrm{cm}^{3}\right)\end{array}$ & $\begin{array}{c}\text { Void } \\
\text { ratio } \\
e_{0}\end{array}$ & $\begin{array}{c}\text { Degree of } \\
\text { saturation } \\
S_{r}(\%)\end{array}$ & $\begin{array}{c}\text { Liquid } \\
\text { limit } \\
\omega_{L}(\%)\end{array}$ & $\begin{array}{c}\text { Plastic } \\
\text { limit } \\
\omega_{P}(\%)\end{array}$ & $\begin{array}{c}\text { Plasticity } \\
\text { index } \\
I_{P}\end{array}$ & $\begin{array}{c}\text { Liquidity } \\
\text { index } \\
I_{L}\end{array}$ & $\begin{array}{c}\text { Compression } \\
\text { coefficient } \\
a_{0.1-0.2} \\
\left(\mathrm{MPa}^{-1}\right)\end{array}$ \\
\hline T3205 & 36.0 & 1.85 & 1 & 98 & 48.8 & 21.9 & 26.9 & 0.52 & 0.983 \\
\hline Т3605 & 32.4 & 1.92 & 0.889 & 100 & 46.3 & 20.1 & 26.2 & 0.47 & 0.905 \\
\hline T3706 & 34.8 & 1.90 & 0.944 & 100 & 43.8 & 22.1 & 21.7 & 0.59 & 0.915 \\
\hline Т3707 & 38.2 & 1.81 & 1.092 & 96 & 50.3 & 24.8 & 25.5 & 0.53 & 0.911 \\
\hline T3709 & 35.8 & 1.86 & 1 & 98 & 47.6 & 21.4 & 26.2 & 0.55 & 0.864 \\
\hline Т3006 & - & - & 0.89 & - & 38.8 & 20.5 & 18.3 & & 0.622 \\
\hline T3813 & - & - & 0.957 & - & 46.8 & 21.3 & 25.5 & & 0.772 \\
\hline
\end{tabular}

TABLE 3: X-ray diffraction analysis of backfill soil minerals.

\begin{tabular}{lccccccc}
\hline Code & Askanite & Quartz & Feldspar & Muscovite & Amphibole & Chlorite & Others \\
\hline T3709 & 25.2 & 35.9 & 15.6 & 8.6 & - & 10.5 & 4.2 \\
T3006 & 19.5 & 35.4 & 20.2 & 11.3 & - & - & 13.6 \\
T3813 & 10.3 & 52.7 & 10.1 & 12.1 & 9.6 & - \\
\hline
\end{tabular}

In order to reveal the embodiment of high compressibility of a certain clay, the characteristics of dynamic change of mesostructural parameters were studied using the continuous test method proposed. According to backfill of 1 meter, the loading scheme confining pressure is $10 \mathrm{kPa}$, and axial pressure is $0 \mathrm{kPa}, 10 \mathrm{kPa}$, and $20 \mathrm{kPa}$. The microscope's magnification is 150 times, and the mesostructures change process is shown in Figure 8. Take T3006 and T3813 as examples, with the load increasing and pores tending to close.

The macroscopic characteristics can be explained at the mesolevel. Quantification of mesostructures' parameters is 


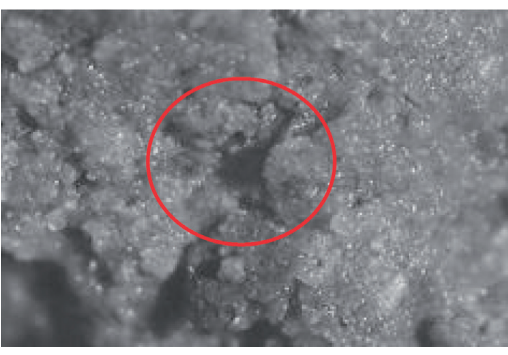

$0 \mathrm{kPa}$

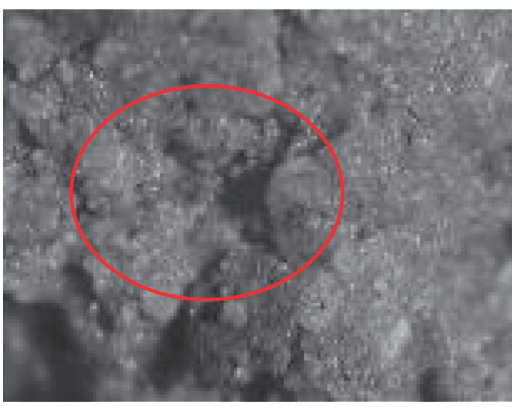

$0 \mathrm{kPa}$

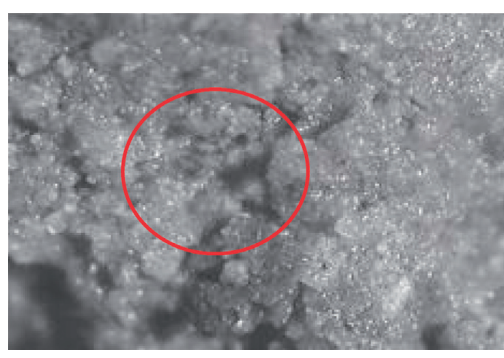

$10 \mathrm{kPa}$

(a)

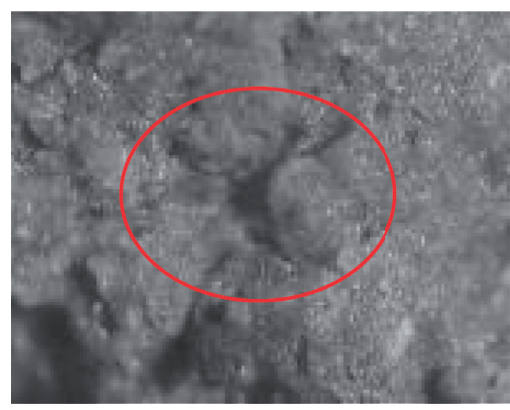

$10 k P a$

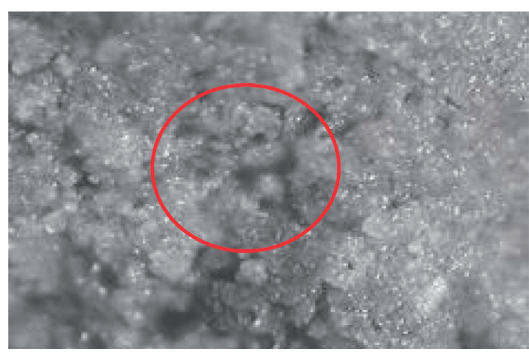

$20 \mathrm{kPa}$

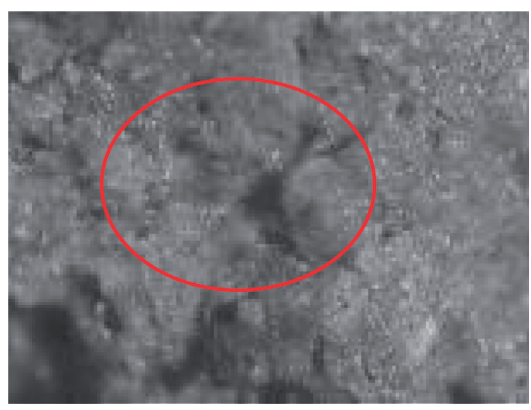

$20 k P a$

(b)

FIgURE 8: The process of the mesostructures change during continuous axial stress: (a) code T3006; (b) code T3813.

obtained using Geo-Image. During the test, as shown in Figure 9(a), the roundness decreased, Figure 9(b) particle number increased, and Figures 9(c) and 9(d) probability entropy and fractal dimension increased. It follows then that the soil mesostructures tend to stabilize, and the soil deformation decreases gradually, while, as shown in Figure 9(e) and Table 2, the higher initial pore, void ratio, and water content will lead to a more significant deformation.

On the other hand, extrastatic pore water pressure increased after loading, and then the pore connectivity enhanced, which is represented as probability entropy of pores increased in Figure 9(f). Furthermore, soil structure becomes looser and messier, and hence compressibility becomes higher. As described above, the causes of high compressibility can be explained from the mesoscopic characterization.

3.2. Shear Zone Development of Cement Soil. The shear band's initiation, development, and breakthrough are typical phenomena for strain localization of soil. The process of initiation of cemented soil shear band could be described through the variation of mesostructures' parameters $[47,48]$. The clay used in the test is quarried from Yunluo Expressway in Guangdong Province. The physical properties of the clay are given in Table 4. Five specimens masses are $153.72 \mathrm{~g}, 163.10 \mathrm{~g}, 173.31 \mathrm{~g}, 183.12 \mathrm{~g}, 192.75 \mathrm{~g}$. Mix cement with soil and stir well, with cement content of $10 \%$, compaction degree of $95 \%$, water binder ratio of $1: 2$, and age of seven days.
Using the proposed method and via the uniaxial compression test on cemented soil specimens, study the regularity of the real mesostructure change of cemented soil in the initiation of the shear band. Use axial strain for shear, i.e., the axial displacement of $2 \mathrm{~mm}$ (strain 2.5\%) each time as $12-15 \mathrm{rpm}$ per minute. Digital image capture uses the strain value of $1 \%$ as the step size before the appearance of the shear band and uses the strain value of $0.2 \%$ as the step size after any shear band is observed. The stress-strain curve of cemented soil is shown in Figure 10. The stress-strain curve of cemented soil can be divided into three stages: the initial loading stage (0-A), the local deformation development stage $(\mathrm{A}-\mathrm{C})$, and the destruction stage $(\mathrm{C}-\mathrm{D})$. The microscope's magnification is 250 times, and the corresponding images of mesostructure change are shown in Figure 11. Figure 11(a) shows microcracks in the specimen before local deformation. As shown in Figure 11(b), after the strain of $2.13 \%$ (point B of Figure 10), the slope of the curve decreased, where microcrack begin to expand, so point B of the stress-strain curve represents the occurrence of the shear band. When axial stress achieves a peak value of $2.69 \%$ (point $\mathrm{C}$ of Figure 10), the soil enters into the destruction stage, where cracks tend to connect as shown in Figures 11(c) and 11(d), and then the width of the shear band expanded to stabilize as shown in Figures 11(e) and 11(f).

In order to have a clearer understanding of the mesostructure evolution of cemented soil, the images use the GeoImage software to extract the parameters for analysis in Figure 12. The development of mesostructure in the shear band has certain regularity. With the axial strains gradually increased, the fissure area ratio gradually increased; 


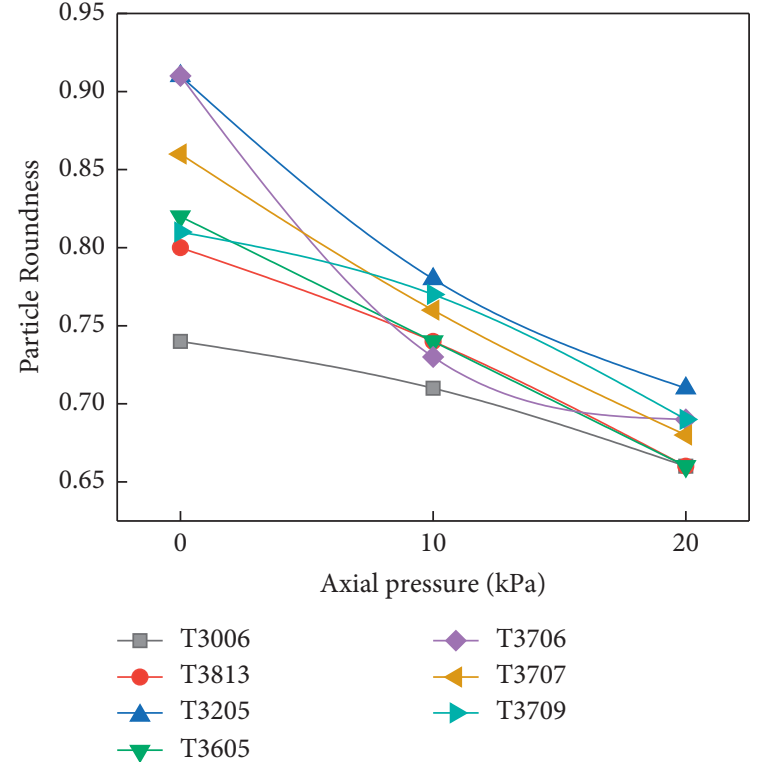

(a)

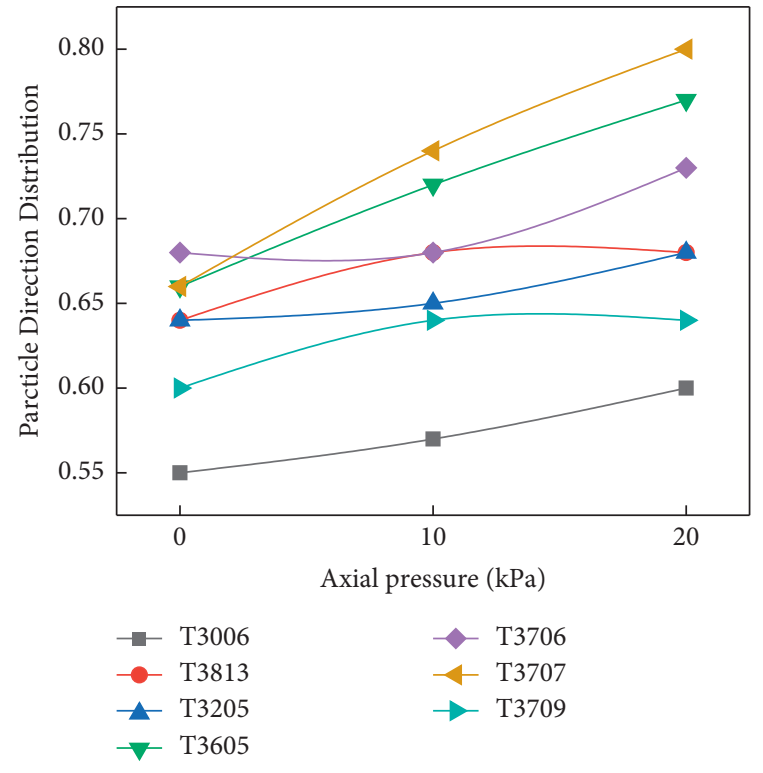

(c)

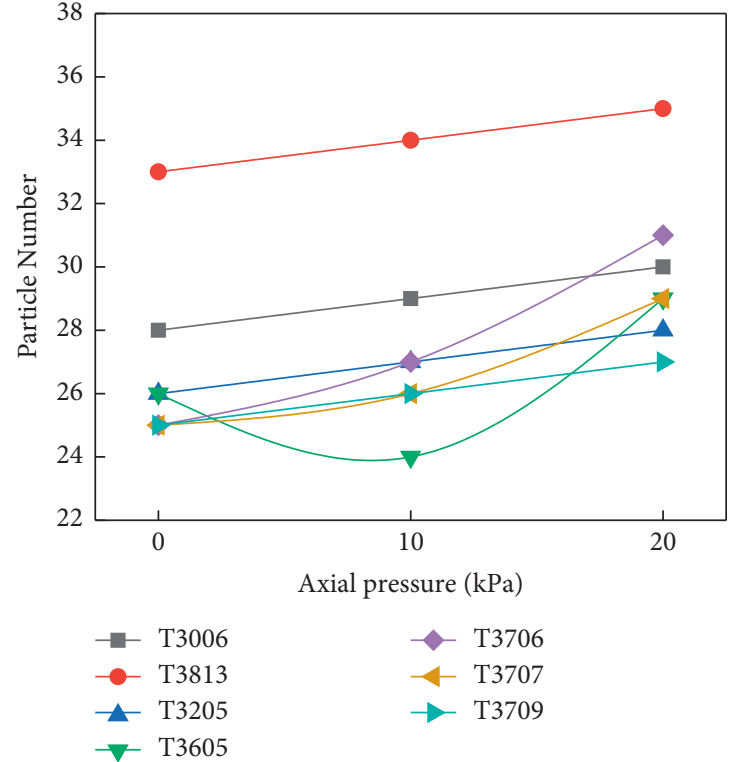

(b)
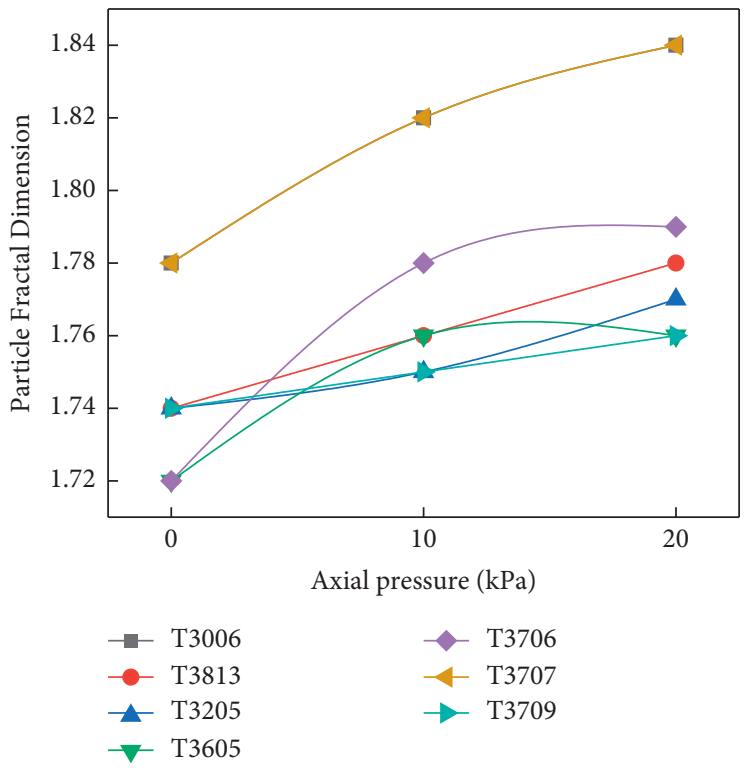

(d)

FIgure 9: Continued. 


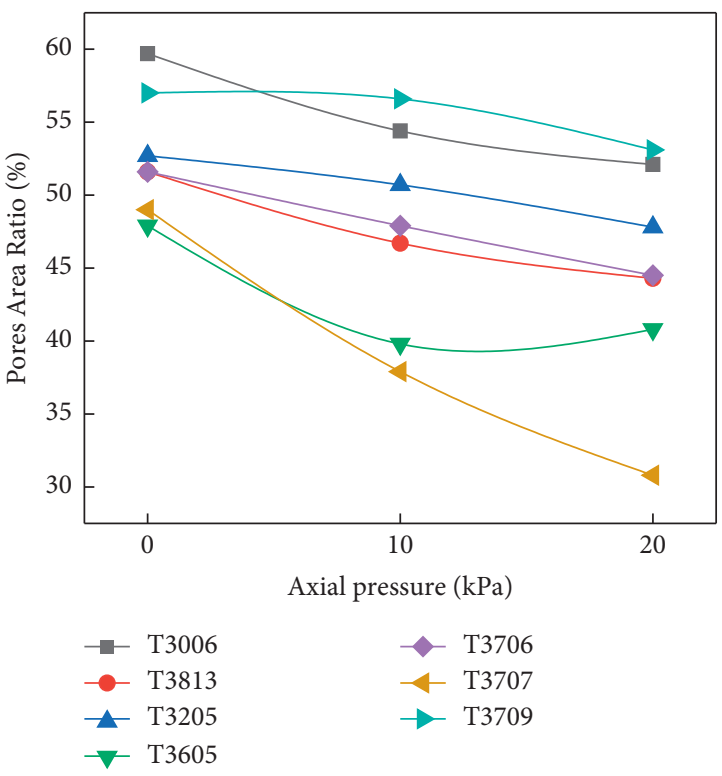

(e)

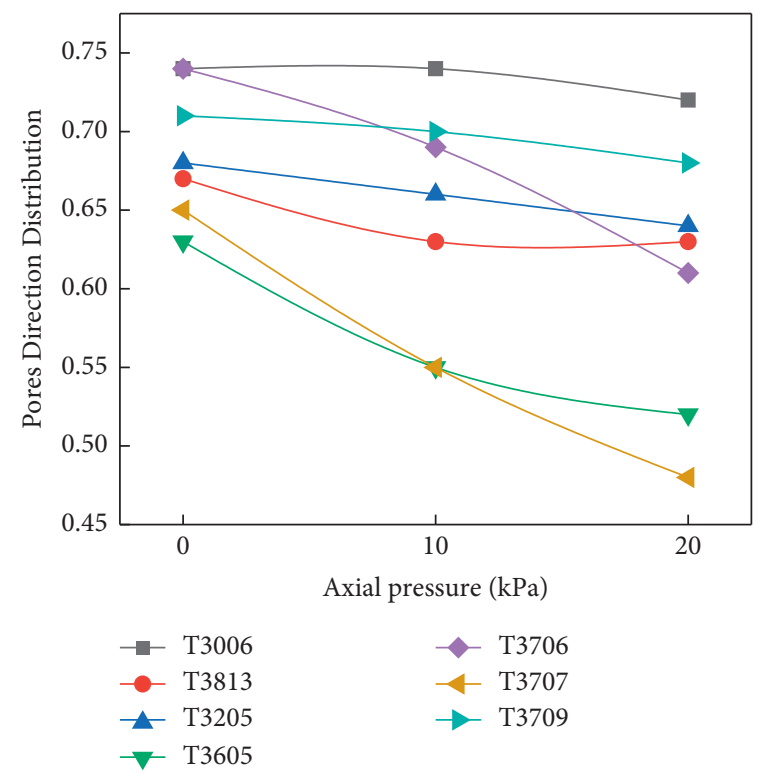

(f)

FIGURE 9: Statistics of the mesostructures' parameters of specimens during load: (a) particle roundness; (b) particles number; (c) particles direction distribution; (d) particle fractal dimension; (e) pores area ratio; (f) pores direction distribution.

TABle 4: Physical properties of the mixed clay.

Specific gravity Plastic limit Liquid limit Plasticity index Free expansion rate Maximum dry density Optimum moisture content

\begin{tabular}{lcccccc}
$G_{S}$ & $\omega_{P}(\%)$ & $\omega_{L}(\%)$ & $I_{P}$ & $\delta_{e f}(\%)$ & $\rho_{d \max }\left(\mathrm{g} / \mathrm{cm}^{3}\right)$ & $\omega_{o p}(\%)$ \\
\hline 2.73 & 28.2 & 57.5 & 29 & 15.3 & 1.698 & 18.2 \\
\hline
\end{tabular}

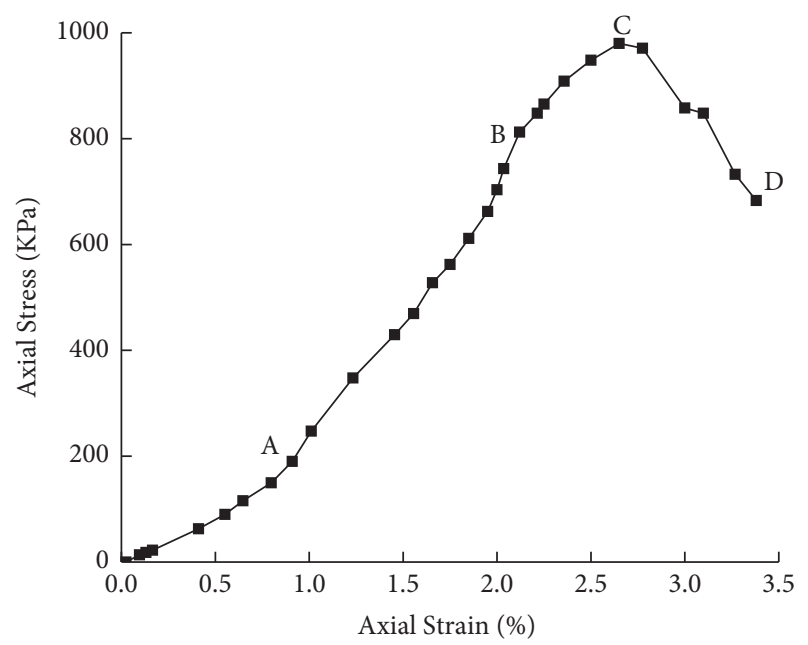

FIGURE 10: The stress-strain curve of cemented soil (cement content $10 \%$, compaction degree $95 \%$, age $7 \mathrm{~d}$ ).

direction distribution, roundness, and fractal dimension of particle decreased gradually. These changes of mesostructure parameters can be used to explain the mechanical mechanism of the shear band at the mesoscale. Due to the heterogeneity of cemented soil, the area with weak connection strength between particles in the sample is disconnected first (Figure 11(a)). As the axial strains increase, the fissure area ratio increases rapidly (Figure 12(a)), that is, initial small cracks propagation as shown in Figures 11(b) and 11(c). After that, the stress concentrates towards this region, which leads to further damage in the region with weak intergranular connections, as shown in Figures 11(d) and 11(e). At this time, the number of particle roundness (Figure 12(b)), direction distribution (Figure 12(a)), and fractal dimension (Figure 12(b)) decreased rapidly, indicating that the particles in the shear band are elongated and aligned directionally. In this way, after the axial strain exceeds $2.9 \%$, as shown in Figure 12, the mesoscopic particle parameters tend to be stable, while the fissure area is still increasing, indicating that the small cracks are linking each other into another large crack at this time (Figure 11(f)).

3.3. Erosive Effects of Ecological Soil. The Dutch [49] proposed ecological soil to reinforce the soft soils, i.e., mixed foam, fibers, microbe, and binder into soft soil. The basic physical parameters and chemical composition of ecological soil are shown in Table 5. In order to study the erosion mechanism of ecological soil in coastal areas (main cation as $\mathrm{Na}+$ and anions as $\mathrm{SO}_{4}^{2-}, \mathrm{Cl}^{-}$) [50] or industrial and agriculture developed area (main anions as $\mathrm{SO}_{4}^{2-}, \mathrm{Cl}^{-}$) [51] soak the specimens in a solution with a $\mathrm{pH}$ of $7,4810 \mathrm{mg} / \mathrm{L}$ concentration of $\mathrm{NaCl}$, and $4440 \mathrm{mg} / \mathrm{L}$ concentration of $\mathrm{Na}_{2} \mathrm{SO}_{4}$.

The dry density (i.e., weight loss rate) in 90 days of the soil specimens is calculated by wet density and water content 


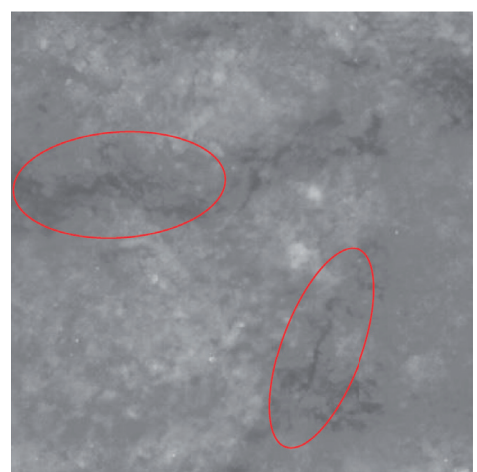

(a)

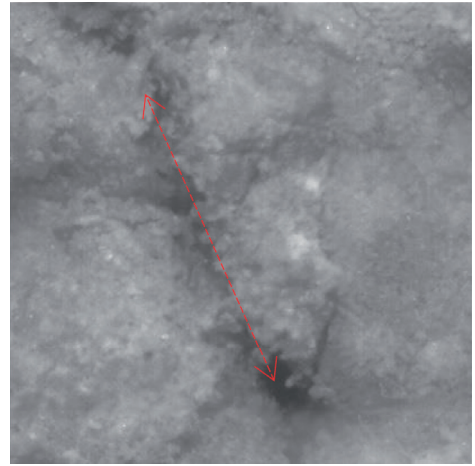

(d)

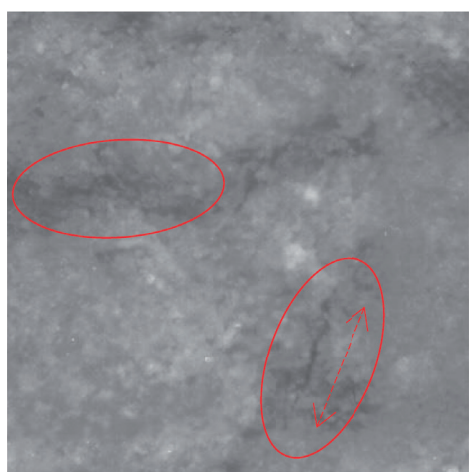

(b)

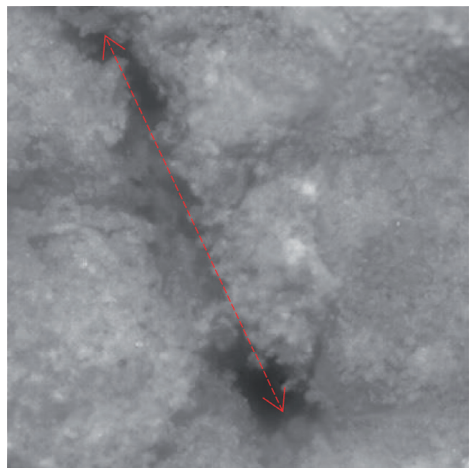

(e)

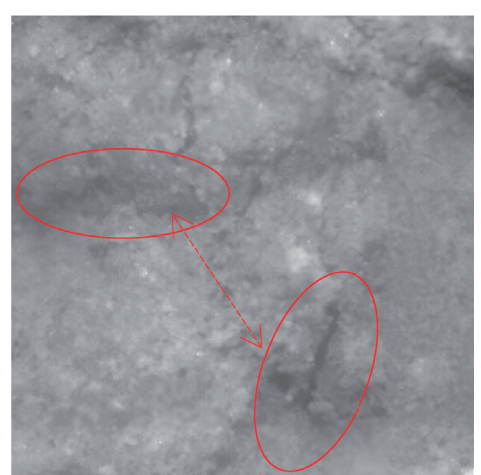

(c)

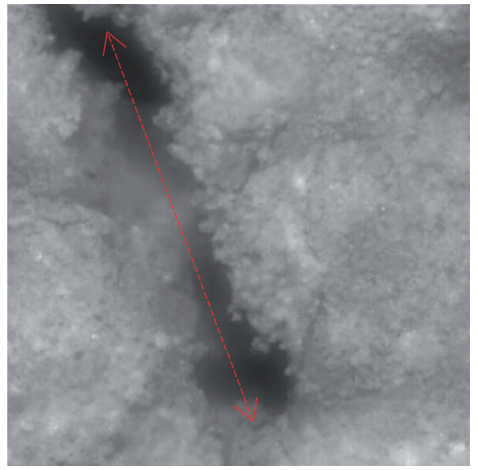

(f)

FIGURE 11: The mesostructure images of the specimen's shear band under different strains: (a) strain 0.91\% (point A of Figure 10); (b) strain $2.13 \%$ (point B of Figure 10); (c) strain 2.5\%; (d) strain 2.69\% (peak value, point C of Figure 10); (e) strain 2.81\%; (f) strain 2.93\%.

TABle 5: Physical properties and chemical composition of ecological soil.

\begin{tabular}{|c|c|c|c|c|c|c|c|c|}
\hline \multicolumn{9}{|c|}{ Basic physical parameters } \\
\hline $\begin{array}{l}\text { Water } \\
\text { content } \omega\end{array}$ & $\begin{array}{c}\text { Specific } \\
\text { gravity } G_{S}\end{array}$ & $\begin{array}{c}\text { Void } \\
\text { ratio } e_{0}\end{array}$ & $\begin{array}{l}\text { Wet density } \rho \\
\left(\mathrm{g} / \mathrm{cm}^{3}\right)\end{array}$ & $\begin{array}{l}\text { Dry density } \rho_{d} \\
\left(\mathrm{~g} / \mathrm{cm}^{3}\right)\end{array}$ & $\begin{array}{c}\text { Plastic limit } \\
\omega_{P}(\%)\end{array}$ & $\begin{array}{c}\text { Liquid limit } \\
\omega_{L}(\%)\end{array}$ & $\begin{array}{l}\text { Plasticity } \\
\text { index } I_{P}\end{array}$ & $\begin{array}{l}\text { Liquidity } \\
\text { index } I_{L}\end{array}$ \\
\hline 182.8 & 0.79 & 0.89 & 1.176 & 0.416 & 170.4 & 197.6 & 27.2 & 0.46 \\
\hline \multicolumn{9}{|c|}{ Chemical composition (\%) } \\
\hline $\mathrm{C}$ & $\mathrm{O}$ & $\mathrm{Na}$ & $\mathrm{Mg}$ & $\mathrm{Al}$ & $\mathrm{Si}$ & $\mathrm{K}$ & $\mathrm{Ca}$ & $\mathrm{Fe}$ \\
\hline 27.7 & 16.7 & 4.3 & 0.5 & 3.3 & 15.6 & 1.5 & 24.5 & 5.9 \\
\hline
\end{tabular}

shown in Figure 13(a). In Figure 13(b), the uniaxial compressive strength of the soil specimens is measured.

The decrease of dry density (i.e., weight loss rate) mainly occurs in the 45 days before, the decrease of strength mainly occurs in the 60 days before, and then both stabilize in Figure 13. In order to explain the macroscopic law during load, take images of mesostructure by SEM in Figure 14 .

Clumps of particle aggregates are gradually diminished, and interaggregate pores are gradually increased. The aggregates and bridges of soil are eroded by $\mathrm{SO}_{4}^{2-}$ and $\mathrm{Cl}^{-}$. And the erosive effects of $\mathrm{NaCl}$ solutions are stronger than $\mathrm{Na}_{2} \mathrm{SO}_{4}$ solutions, which means the erosive effects of $\mathrm{Cl}^{-}$ solutions are stronger than $\mathrm{SO}_{4}^{2-}$ on the ecological soil. Thus, the mesostructure is looser and has low stability in $\mathrm{NaCl}$ solutions.

To have a clearer understanding of the erosive effects of ecological soil, the images of SEM use the Geo-Image software to extract the parameters for analysis in Figure 15.

The mesostructure parameters have obvious regularity. The particle area ratio in $\mathrm{NaCl}$ solution is decreased more than $\mathrm{Na}_{2} \mathrm{SO}_{4}$ solution, and Euler number is increased more with the increase of soaking time. Again, the erosive effects of $\mathrm{Cl}^{-}$solutions are stronger than $\mathrm{SO}_{4}^{2-}$ on the ecological soil at the mesoscopic level. Therefore, the measures against 


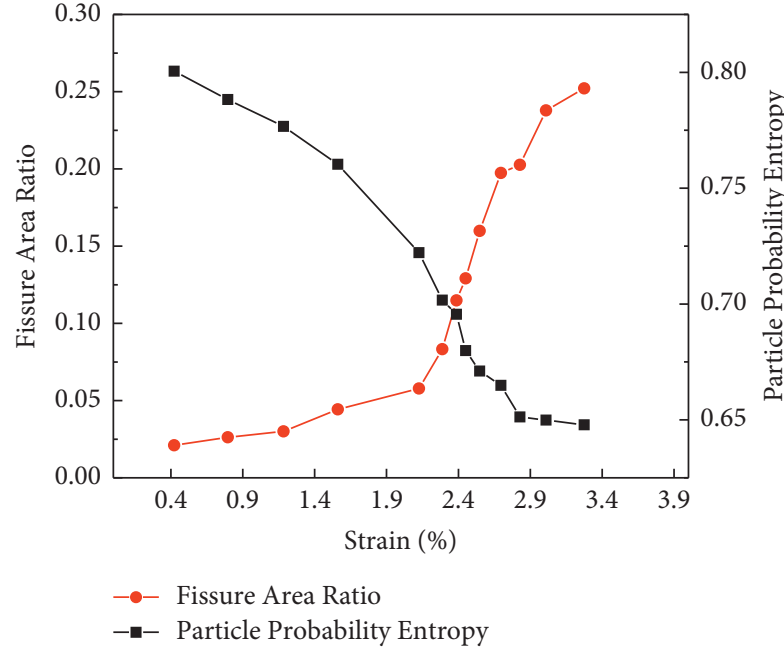

(a)

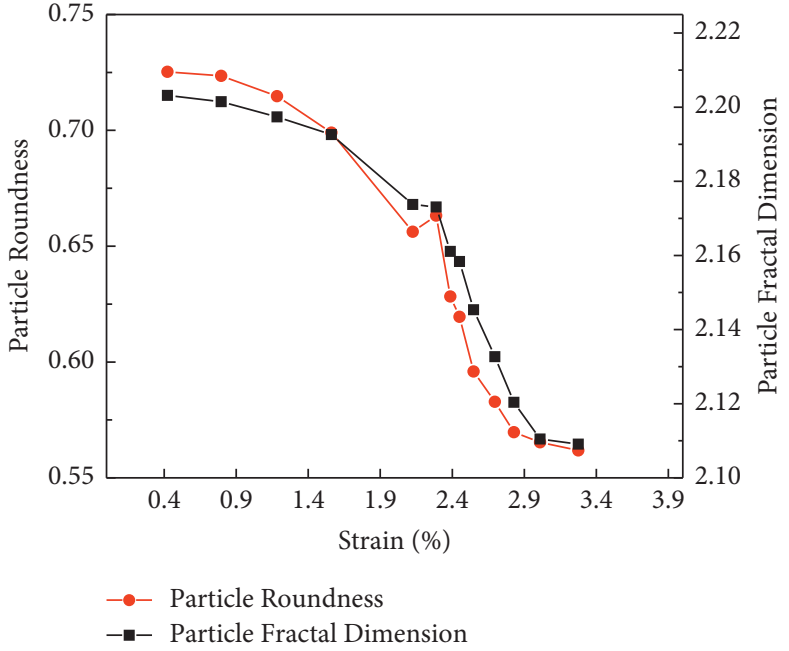

(b)

FIGURE 12: Statistics of the mesostructure's parameters of cement soils during the uniaxial compression test: (a) fissure area ratio and particle direction distribution; (b) particle roundness and fractal dimension.

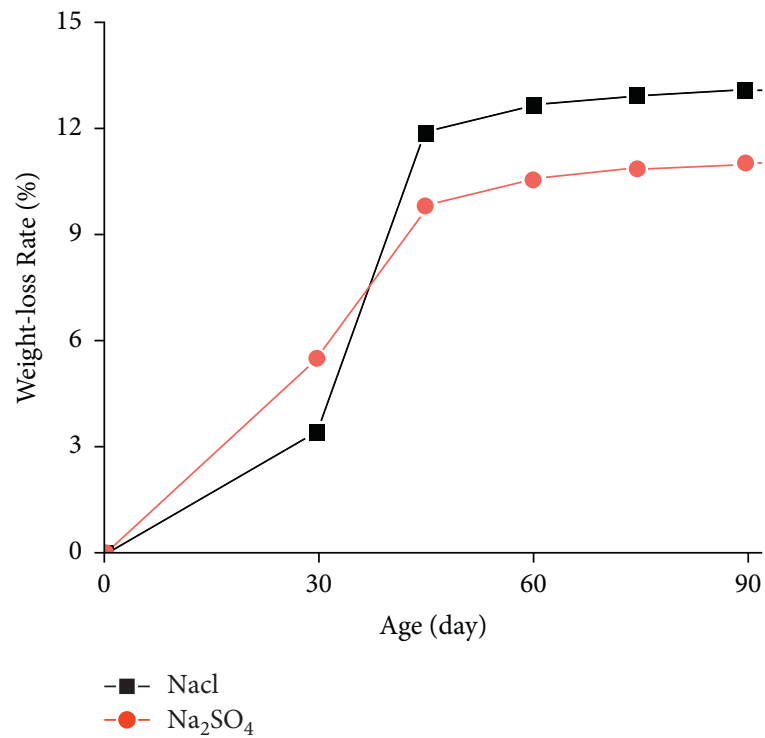

(a)

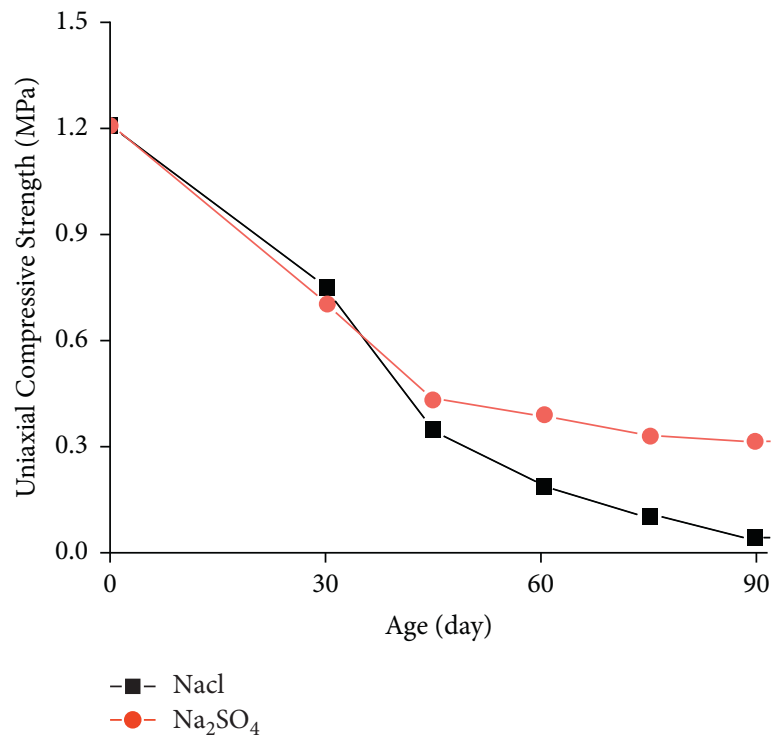

(b)

FIGURE 13: Relation curve between age and weight loss rate and uniaxial compressive strength of ecological soil under corrosive action: (a) relation curve between age and weight loss rate; (b) relation curve between age and uniaxial compressive strength. 


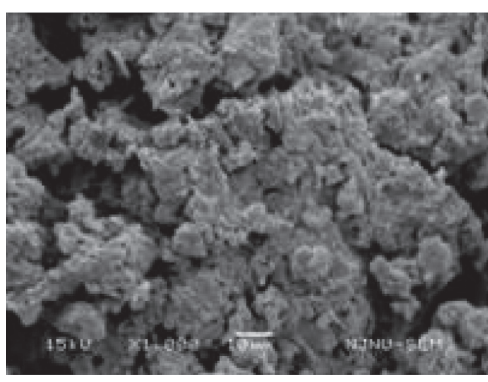

0 day

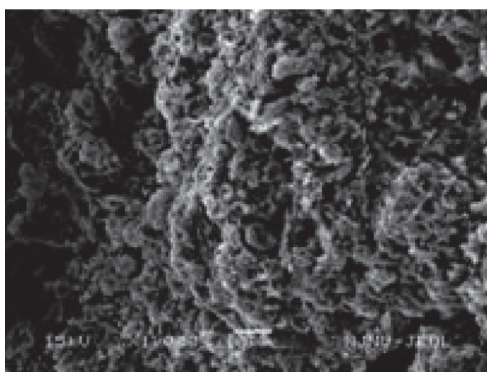

60 days

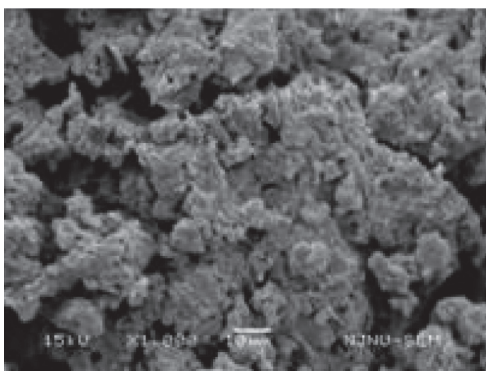

0 day

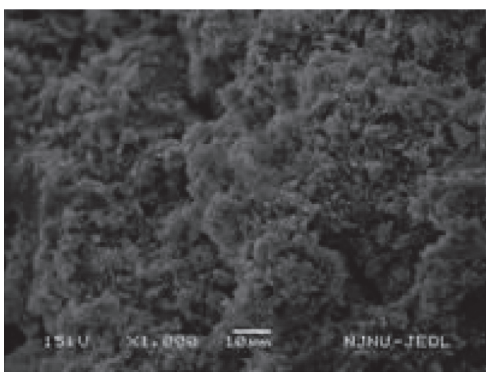

60 days

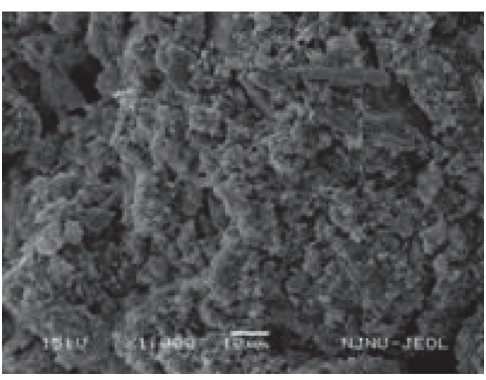

30 days

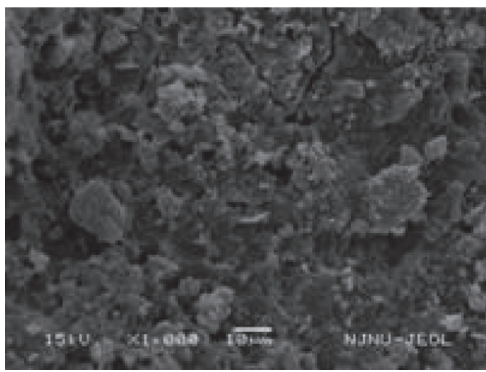

75 days

(a)

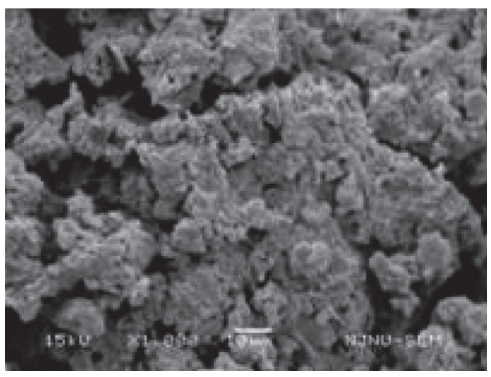

30 days

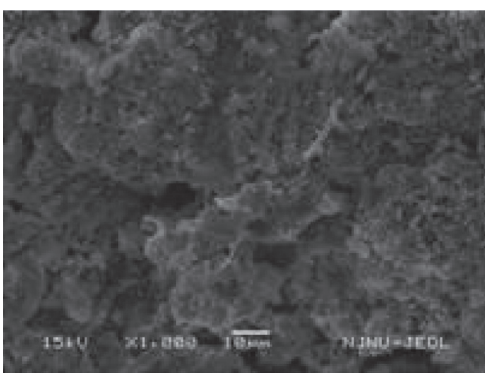

75 days

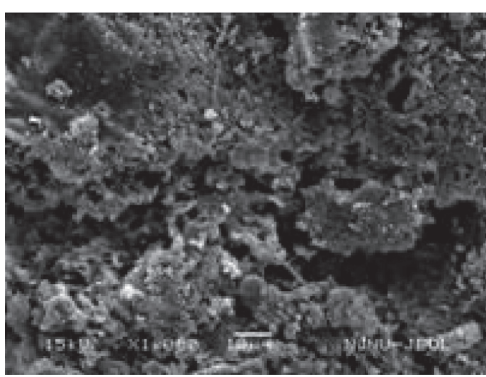

45 days

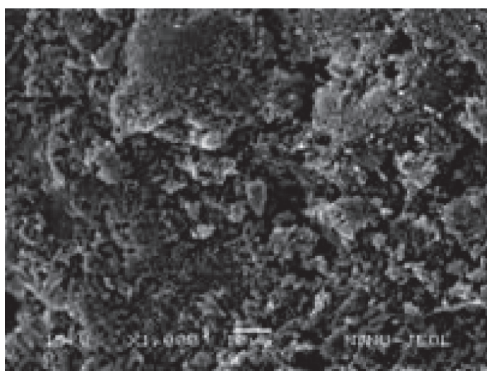

90 days

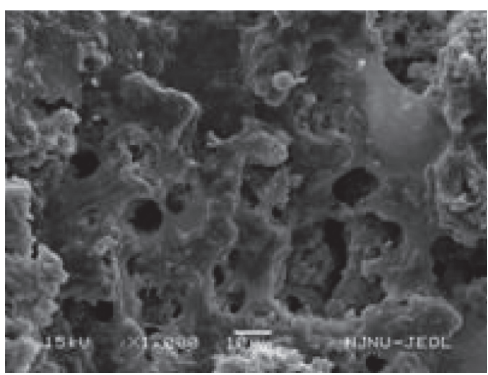

45 days

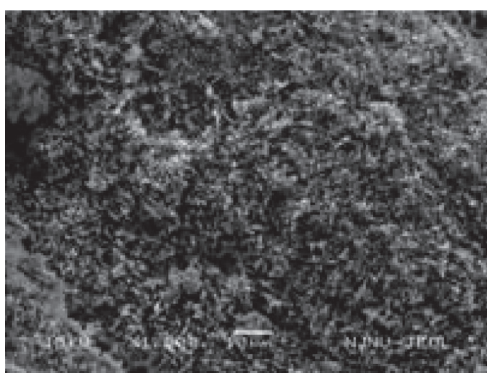

90 days

(b)

Figure 14: Mesoscopic images of ecological soil soaked in prepared solution on 90 days: (a) mesoscopic images of ecological soil marinated in $\mathrm{NaCl}$ solution; (b) mesoscopic images of ecological soil marinated in $\mathrm{Na}_{2} \mathrm{SO}_{4}$ solution. 


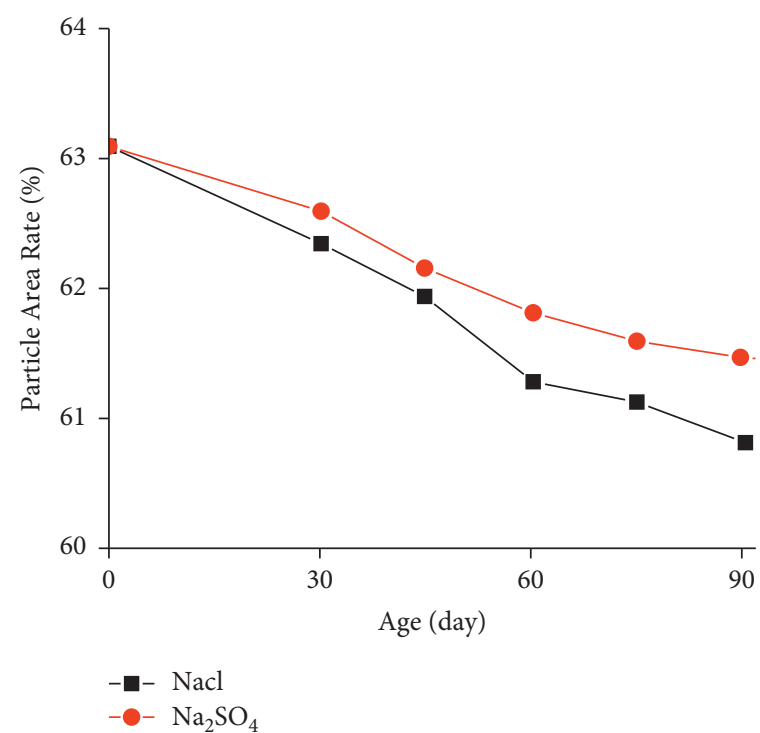

(a)

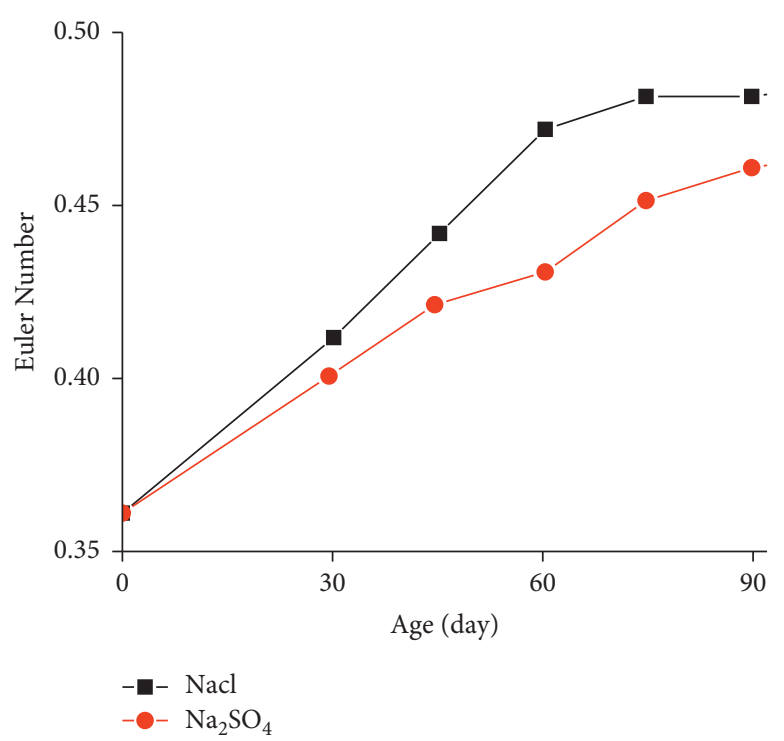

(b)

FIGURE 15: Statistics of the mesostructure's parameters of ecological soil under corrosive action: (a) relation curve between age and particle area rate; (b) relation curve between age and Euler number.

must be taken when ecological soil reinforced the soft soil in coastal areas or industrial and agriculture developed areas.

\section{Conclusions}

A continuous test method and equipment are proposed, which can realize the macro- and mesointegrated observation. A semicylindrical pressure chamber with transparent tempered glass is produced, which realizes the direct observation of the internal structure of soils, equipped with a noncontact microscope and CCD camera that realized mesostructure's measurement, by tracking clusters of uniquely colored pixels to realize tracking of objects and transform the relative distance of pixel subset into pulse number of stepping motor control driver to realize the autotracking by microscope. Based on image processing technologies as image fusion and image segmentation, identify and extract the characterization of mesostructural parameters such as area ratio, fractal dimension, direction distribution, roundness, and Euler number for dynamic change of real mesostructure research. By combining conventional triaxial test equipment, a self-designed semicylindrical loading chamber, and the automatic image tracking technology, we realize the macro-meso-integrated measurement.

In order to verify the feasibility and effectiveness of the proposed method, the macro- and mesocharacteristics of soil samples are measured by the proposed method, which cannot be explained from the macroscopic level, for example, the reason of the high compressibility of a certain clay; shear zone development of cement soil; erosive effects of ecological soil. By obtaining the dynamic change of real mesostructure parameters, the mechanism of soil macroscopic characteristics can be revealed from the mesolevel.

\section{Data Availability}

The datasets supporting the conclusions of this article are included within the article.

\section{Conflicts of Interest}

The authors declare that there are no conflicts of interest.

\section{Acknowledgments}

This study was sponsored by the National Natural Science Foundation of China (Grant no. 51609071), Fundamental Research Funds for the Central Universities (Grant nos. B200202087 and B200204032), Young Scientists Fund of the National Natural Science Foundation of China (Grant no. 51908278), Natural Science Foundation of the Jiangsu Higher Education Institutions of China (Grant no. 19KJD410002), and Jiangsu Students' Platform for Innovation and Entrepreneurship Training Program (Grant no. 202113646014Y).

\section{References}

[1] F. Cotecchia, G. Mitaritonna, and C. Vitone, "Investigating the influence of microstructure, loading history and fissuring on the clay response," in Proceedings of the 5th International Symposium on Deformation Characteristics of Geomaterials, Seoul, Korea, August 2011.

[2] G. Guida, G. M. B. Viggiani, and F. Casini, "Multi-scale morphological descriptors from the fractal analysis of particle contour," Acta Geotechnica, vol. 15, no. 5, pp. 1067-1080, 2020.

[3] G. Zhang, G. Wang, Z. Y. Yin, and Z. X. Yang, "A critical review on the research of fundamental behavior and constitutive relationship of the soil," China Civil Engineering Journal, vol. 53, no. 2, pp. 105-118, 2020. 
[4] C. Zhou, G. Cui, W. Liang, Z. Liu, and L. Zhang, "A coupled macroscopic and mesoscopic creep model of soft marine soil using a directional probability entropy approach," Journal of Marine Science and Engineering, vol. 9, no. 2, p. 224, 2021.

[5] H. Z. Su, Z. Q. Fu, A. Gao, and Z. P. Wen, "Numerical simulation of soil levee slope instability using particle-flow code method," Natural Hazards Review, vol. 20, no. 2, Article ID 4019001, 2019.

[6] Y. Zhang, S. Zuo, R. Y. M. Li, Y. Mo, G. Yang, and M. Zhang, "Experimental study on the mechanical properties of Guiyang red clay considering the meso micro damage mechanism and stress path," Scientific Reports, vol. 10, no. 1, 2020.

[7] X. Wei, K. V. Bicalho, A. El Hajjar, S. Taibi, M. Hattab, and J. M. Fleureau, "Experimental techniques for the study of the cracking mechanisms in drying clays," Geotechnical Testing Journal, vol. 44, no. 2, Article ID 20190430, 2021.

[8] L. T. Shao, G. Liu, F. Zeng, and X. Guo, "Recognition of the stress-strain curve based on the local deformation measurement of soil specimens in the triaxial test," Geotechnlcal Testing Journal, vol. 39, no. 4, pp. 658-672, 2016.

[9] W. Wang, B. H. Zhao, B. Zhao, L. Yu, and D. Zang, "Research on a numerical model of real mesostructures in the non-shear zone of clay," Acta Geotechnica Slovenica, vol. 16, no. 2, pp. 66-76, 2019.

[10] H. Zhou, Y. G. Fang, R. G. Gu, and C. Zeng, "Microscopic analysis of saturated soft clay in pearl river delta," Journal of Central South University, vol. 18, no. 2, pp. 504-510, 2011.

[11] M. J. Jiang, "New paradigm for modern soil mechanics: geomechanics from micro to macro," Chinese Journal of Geotechnical Engineering, vol. 41, no. 2, pp. 195-254, 2019.

[12] C. Liu, B. Shi, J. Zhou, and C. Tang, "Quantification and characterization of microporosity by image processing, geometric measurement and statistical methods: application on SEM images of clay materials," Applied Clay Science, vol. 54, no. 1, pp. 97-106, 2011.

[13] F. Cotecchia, S. Guglielmi, F. Cafaro, and A. Gens, "Characterisation of the multi-scale fabric features of high plasticity clays," Géotechnique Letters, vol. 9, no. 4, pp. 361-368, 2019.

[14] R. Alikarami, E. Andò, M. G. Kapnisis, A. Torabi, and G. Viggiani, "Strain localisation and grain breakage in sand under shearing at high mean stress: insights from in situ X-ray tomography," Acta Geotechnica, vol. 10, no. 1, pp. 15-30, 2015.

[15] S. Q. Yang, P. G. Ranjith, and Y. L. Gui, "Experimental study of mechanical behavior and $\mathrm{x}$-ray micro ct observations of sandstone under conventional triaxial compression," Geotechnical Testing Journal, vol. 38, no. 2, Article ID 20140209, 2015.

[16] H. Sun, Y. Gao, X. Zheng, Y. Chen, Z. Jiang, and Z. Zhang, "Meso-scale simulation of concrete uniaxial behavior based on numerical modeling of ct images," Materials, vol. 12, no. 20, 3403 pages, 2019.

[17] B. Zhao, J. Wang, M. R. Coop, G. Viggiani, and M. Jiang, “An investigation of single sand particle fracture using X-ray micro-tomography," Géotechnique, vol. 8, no. 65, pp. 625-641, 2015.

[18] Z. Chen, M. Omidvar, and M. Iskander, "Observations of multi-scale granular kinematics around driven piles in plane strain condition," Geotechnical Testing Journal, vol. 39, no. 5, Article ID 20150199, 2016.

[19] S. X. Feng, J. R. Chai, Z. G. Xu, Y. Qin, and Y. L. Li, "Test study on the suffusion process of sand-rock mixtures by nmr systems," Geotechnical Testing Journal, vol. 43, no. 5, Article ID 20180208, 2020.
[20] F. Q. Yang, D. H. Zhang, K. D. Huang, Z. Z. Gao, and J. M. Liao, "Review of the effect of computed tomography projection sampling strategy on reconstruction quality," Journal of Software, vol. 29, no. 7, pp. 2133-2151, 2018.

[21] P. Shan and X. Lai, "Influence of CT scanning parameters on rock and soil images," Journal of Visual Communication and Image Representation, vol. 58, pp. 642-650, 2019.

[22] X. Zhang, L. Li, G. Chen, and R. Lytton, "A photogrammetrybased method to measure total and local volume changes of unsaturated soils during triaxial testing," Acta Geotechnica, vol. 10, no. 1, pp. 55-82, 2015.

[23] M. Sutton, W. Wolters, W. Peters, W. Ranson, and S. McNeill, "Determination of displacements using an improved digital correlation method," Image and Vision Computing, vol. 1, no. 3, pp. 133-139, 1983.

[24] S. E. Salazar, "Development of an internal camera-based volume determination system for triaxial testing," ProQuest Dissertations \& Theses, Proquest, Ann Arbor, MI, 2017.

[25] L. Li and X. Zhang, "Factors influencing the accuracy of the photogrammetry-based deformation measurement method," Acta Geotechnica, vol. 14, no. 2, pp. 559-574, 2019.

[26] S. E. Salazar, L. D. Miramontes, A. Barnes, M. L. BernhardtBarry, and R. A. Coffman, "Verification of an internal closerange photogrammetry approach for volume determination during triaxial testing," Geotechnical Testing Journal, vol. 42, no. 6, pp. 1640-1662, 2019.

[27] K. A. Alshibli and S. Sture, "Sand shear band thickness measurements by digital imaging techniques," Journal of Computing in Civil Engineering, vol. 13, no. 2, pp. 103-109, 1999.

[28] P. J. Withers, "Strain measurement by digital image correlation," Strain, vol. 46, no. 6, pp. 421-422, 2008.

[29] A. Uchaipichat, N. Khalili, and S. Zargarbashi, "A temperature controlled triaxial apparatus for testing unsaturated soils," Geotechnical Testing Journal, vol. 34, no. 5, pp. 424-432, 2011.

[30] Q. Zhang, G. Yin, Z. Wei, X. Fan, W. Wang, and W. Nie, "An experimental study of the mechanical features of layered structures in dam tailings from macroscopic and microscopic points of view," Engineering Geology, vol. 195, pp. 142-154, 2015.

[31] H. Tang, T. Du, L. Zhang, and L. Shao, "A plane strain testing apparatus characterized by flexible loading and noncontact deformation measurement and its application to the study of shear band failure of sand," International Journal of Distributed Sensor Networks, vol. 14, no. 9, 2018.

[32] P. Wang, Y. Sang, L. Shao, and X. Guo, "Measurement of the deformation of sand in a plane strain compression experiment using incremental digital image correlation," Acta Geotechnica, vol. 14, no. 2, pp. 547-557, 2019.

[33] Y. Tang, S. Okubo, J. Xu, and S. Peng, "Progressive failure behaviors and crack evolution of rocks under triaxial compression by $3 \mathrm{D}$ digital image correlation," Engineering Geology, vol. 249, pp. 172-185, 2019.

[34] A. L. Rechenmacher and Z. M. Cetina, "Calibration of soil constitutive models with spatially varying parameters," Journal of Geotechnical and Geoenvironmental Engineering, vol. 133, no. 12, pp. 1567-1576, 2007.

[35] W. Lanting, X. Qiang, W. Shanyong, W. Cuilin, and J. Xu, "The morphology evolution of the shear band in slope: insights from physical modelling using transparent soil," Bulletin of Engineering Geology and the Environment, vol. 79, no. 4, pp. 1849-1860, 2020. 
[36] S. E. Salazar and R. A. Coffman, "Consideration of internal board camera optics for triaxial testing applications," Geotechnical Testing Journal, vol. 38, no. 1, Article ID 20140163, 2015.

[37] A. Mehdizadeh, M. M. Disfani, R. P. Evans, A. Arulrajah, and D. E. L. Ong, "Discussion of 'development of an internal camera-based volume determination system for triaxial testing' by S. E. Salazar, A. Barnes and R. A. Coffman," Geotechnical Testing Journal, vol. 38, no. 1, pp. 165-168, 2015.

[38] J. M. Sergeev, V. I. Osipov, and V. N. Sokolov, "Quantitative analysis of soil structure with the microcomputer system," Bulletin of the International Association of Engineering Geology, vol. 1, no. 31, pp. 131-136, 1985.

[39] J. Liu and X. G. Fang, "Constitutive relation of soil cell element model," Electronic Journal of Geotechnical Engineering, vol. 18, pp. 2675-2682, 2013.

[40] Y. G. Fang, J. Liu, and Z. L. Dong, "Soil elastic-plastic rotation gradient theory based on grain size factor and its finite element implementation," Advanced Materials Research, vol. 779-780, pp. 420-424, 2013.

[41] M. A. Sutton, S. R. McNeill, J. D. Helm, and Y. J. Chao, Advances in Two-Dimensional and Three-Dimensional Computer Vision, pp. 323-372, Springer, Berlin, Germany, 2000.

[42] O. Zaid and S. Tania, "Image fusion: an overview," in Proceedings of the 2014 5th International Conference on Intelligent Systems, Modelling and Simulation, pp. 306-310, Langkawi Malaysia, January 2014.

[43] C. S. Tang, B. Shi, and B. J. Wang, "Factors affecting analysis of soil microstructure using SEM," Chinese Journal of Geotechnical Engineering, vol. 30, no. 04, pp. 560-565, 2008.

[44] N. S. Chinese, Standard for Engineering Classification of SoilChina Planning Press, Beijing, China, 2007.

[45] N. S. Chinese, Test Methods of Soils for Highway EngineeringResearch Institute of Highway Science, Ministry of Transport, Beijing, China, 2020.

[46] S. X. Yan, Y. Y. Qu, and S. J. Han, "A study on the relationship between smectite content andswell potential indices," Journal of Engineering Geology, vol. 12, no. 1, pp. 328-336, 2005.

[47] X. Liu, L. Q. Gan, H. Shan, K. Sheng, and B. N. Hong, "Mesoscopic uniaxial compression test research on initiation process of shear band in cemented soil," Journal of Computational and Theoretical Nanoscience, vol. 13, no. 4, pp. 2677-2683, 2016.

[48] W. Wang, B. H. Zhao, L. W. Yu, and D. H. Zhang, "Application of duncan-chang model on the numerical analysis considering the clay heterogeneity," Acta Geotechnical Slovenica, vol. 16, no. 2, pp. 66-76, 2018.

[49] Q. Sun, X. Liu, B. N. Hong, and X. Hu, "Evolution characteristics of microstructure of smart soil under uniaxial stress," Journal of Wuhan University of Technology, vol. 34, no. 8, pp. 92-96, 2012.

[50] N. C. Mondal, V. P. Singh, V. S. Singh, and V. K. Saxena, "Determining the interaction between groundwater and saline water through groundwater major ions chemistry," Journal of Hydrology, vol. 388, no. 1-2, pp. 100-111, 2010.

[51] J. Y. Zhang, S. L. Chen, J. J. Shi, Y. H. Wu, Y. L. Yang, and $\mathrm{X}$. Wei, "Erosion effects of sodium sulfate solution on the unconfined compression strength of cement soil," Advanced Materials Research, vol. 1065-1069, pp. 123-127, 2014. 